\title{
Pengaruh Rendam Kaki Air Hangat Terhadap Pemenuhan Tidur Pada Pasien Preoperatif di RSU Dr. H. Koesnadi
}

\author{
Fitriana Putri ${ }^{1}$, Ns. Luh Titi Handayani ${ }^{2}$, Muhammad Amin Huda ${ }^{1}$ \\ Universitas Muhammadiyah Jember \\ Email: fikes@unmuhjember.ac.id
}

\begin{abstract}
Pre-operative phase is one of the conditions that can cause anxiety, especially patients with elective surgery. Anxiety makes a person have trouble sleeping, often waking at midnight, and changing sleep cycles, so the sleep needs are not met. One of non-pharmacological therapy that sleep needs are met is a foot bath with warm water. The purpose of this study is to identify of influence of foot soak with warm water toward fulfillment of sleep need on Preoperative Patient at Dahlia Room RSU Dr. H. Koesnadi Bondowoso. The research design was pretest-posttest With Control Group Design. Total population 28 patients and samples in this study were drawn from the entire population of 28 respondents using total sampling technique. The results statistically using Mann Whitney test with $\alpha=0.05 p$ value 0,003, so it can be concluded that there is influence of foot soak with warm water toward fulfillment of sleep need on Preoperative Patient at Dahlia Room RSU Dr. H. Koesnadi Bondowoso. This study was recommended to nurses to be able to apply the foot bath of warm water in the patient's preoperative so that his needs are met so that the body is still functioning properly in preparation for surgery.
\end{abstract}

Key word: Foot soak, Sleep need, Pre-operative

\section{Pendahuluan}

Pembedahan merupakan tindakan medis yang penting dalam pelayanan kesehatan dan salah satu tindakan yang bertujuan untuk menyelamatkan nyawa, mencegah kecacatan dan komplikasi (Hasri, et al. 2012). Fase preoperatif adalah waktu sejak keputusan untuk operasi diambil hingga sampai ke meja pembedahan, tanpa memandang riwayat atau klasifikasi pembedahan (Muttaqin dan Sari, 2009).

Fase preoperatif merupakan salah satu kondisi yang dapat menimbulkan kecemasan, khususnya pasien dengan pembedahan elektif (Stuart, 2014). Hal ini disebabkan karena ketidaktahuan tentang konsekuensi pembedahan dan rasa takut terhadap prosedur pembedahan itu sendiri (Muttaqin dan Sari, 2009).

Kecemasan yang dialami seseorang karena masalah yang dihadapinya membuat seseorang menjadi tegang dan berusaha keras untuk tertidur sehingga stres yang berlanjut dapat menyebabkan seseorang mempunyai kebiasaan tidur yang buruk. Perasaan cemas akan hal yang dialaminya membuat seseorang sulit tidur, sering terbangun tengah malam, perubahan siklus tidur, bahkan terlalu banyak tidur sehingga stres emosional dapat menyebabkan kebiasaan tidur buruk (Potter dan Perry, 2009).

Pemenuhan kebutuhan tidur sangat penting bagi pasien Preoperatif. Tidur dapat memperbaiki fungsi imunitas, restorasi suhu, homeostasis dan regulasi suhu (Lumbantobing, 2008). Hal ini sangat diperlukan oleh pasien yang akan menjalani pembedahan. Karena selain memerlukan pemenuhan nutrisi dan keadaan psikosoial yang baik, pasien preoperatif memerlukan pemenuhan tidur yang cukup untuk menjaga agar tubuh tetap berfungsi dengan baik (Baradero et al, 2009).

Untuk meningkatkan kuantitas maupun kualitas tidur dapat menggunakan terapi farmakologi maupun non-farmakologi. Salah satu terapi non-farmakologi untuk pemenuhan kebutuhan tidur ialah rendam kaki menggunakan air hangat. Merendam kaki dengan air hangat dapat meningkatkan kualitas tidur (Utami, 2015).

Rendam air hangat pada kaki merupakan teknik stimulasi tidur yang dilakukan dengan cara merendam kaki pada air hangat bersuhu $37^{\circ} \mathrm{C}-39^{\circ} \mathrm{C}$ (Utami, 2015). Hal ini sesuai 
berdasarkan fisiologi bahwa pada daerah kaki terdapat syaraf-syaraf kulit yaitu flexusvenosus dari rangkaian syaraf ini stimulasi diteruskan ke kornus posterior kemudian dilanjutkan ke medulla spinalis, dari sini diterukan ke lamina I, II, III radiks dorsalis, selanjutnya ke ventro basal thalamus dan masuk ke batang otak yang tepatnya didaerah raafe bagian bawah pons dan medulla disinilah terjadi efek sofarifik (ingin tidur) (Guyton 2007 dalam Ningtyas, 2014).

Pasien Preoperatif (bedah elektif) di RSU DR. H. Koesnadi selama bulan Juli sampai September 2015 yaitu sejumlah 86 pasien. Pada hasil wawancara yang dilakukan pada pasien preoperatif di RSU DR. H. Koesnadi didapatkan bahwa 8 dari 10 pasien preoperatif mengalami gangguan tidur.

Berdasarkan permasalahan di atas, peneliti ingin melakukan penelitian dengan judul "Pengaruh Rendam Kaki dengan Air Hangat Terhadap Pemenuhan Kebutuhan Tidur pada Pasien Preoperatif di Ruang Dahlia RSU DR. H. Koesnadi Bondowoso.

\section{Tujuan Penelitian}

\subsection{Tujuan Umum}

Mengidentifikasi pengaruh rendam kaki dengan air hangat terhadap pemenuhan kebutuhan tidur pada pasien preoperatif di Ruang Dahlia RSU DR. H. Koesnadi Bondowoso.

\subsection{Tujuan Khusus}

a. Mengidentifikasi pemenuhan kebutuhan tidur pasien preoperatif pada kelompok kontrol di Ruang Dahlia RSU DR. H. Koesnadi Bondowoso.

b. Mengidentifikasi pemenuhan kebutuhan tidur pasien preoperatif pada kelompok perlakuan di Ruang Dahlia RSU DR. H. Koesnadi Bondowoso.

c. Menganalisis pengaruh rendam kaki dengan air hangat terhadap pemenuhan kebutuhan tidur pada pasien preoperatif di Ruang Dahlia RSU DR. H. Koesnadi Bondowoso.

\section{Metode Penelitian}

Penelitian ini dilakukan di Ruang Dahlia RSU DR. H. Koesnadi Bondowoso. Waktu penelitian dilakukan pada bulan April 2016. Desain penelitian yang digunakan ialah
Pretest-Postest With Control Group Design yaitu dengan memberikan treatment pada kelompok perlakuan dan tidak memberikan treatment pada kelompok kontrol. Populasi dalam penelitian ialah semua Pasien Preoperatif (pembedahan elektif) di Ruang Dahlia RSU Dr. H. Koesnadi Bondowoso dalam satu bulan yaitu sejumlah 28 Pasien. Sampel penelitian didapatkan melalui total sampling yaitu dengan mengambil dari keseluruhan populasi.

Pengumpulan data didapatkan melalui kuesioner dan observasi. Kuesioner terdiri dari 9 pertanyaan yang terdiri dari parameter kualitas tidur subjektif, latensi tidur dan durasi tidur. Sedangkan observasi terdiri dari 5 kriteria tanda dan gejala gangguan pemenuhan tidur.

Analisa yang digunakan berupa analisa univariat dan bivariat. Analisa univariat digunakan untuk mendeskripsikan data demografi dengan menggunakan distribusi frekuensi. Sedangkan analisa bivariat digunakan untuk mengetahui beda antara kelompok kontrol dengan kelompok perlakuan dengan menggunakan Uji Mann-Whitney dengan ketentuan nilai $\alpha=0,05$.

\section{Hasil dan Pembahasan 4.1 Hasil Penelitian}

Tabel 5.4 Distribusi Frekuensi Hasil Pretest Pemenuhan Kebutuhan Tidur

\begin{tabular}{|c|c|c|c|c|c|}
\hline \multirow{3}{*}{$\begin{array}{c}\text { Kelompo } \\
\mathbf{k}\end{array}$} & \multicolumn{4}{|c|}{$\begin{array}{c}\text { Pemenuhan } \\
\text { Kebutuhan Tidur }\end{array}$} & \multirow{3}{*}{$\mathbf{P}$} \\
\hline & \multicolumn{2}{|c|}{ Terpenuhi } & \multicolumn{2}{|c|}{$\begin{array}{c}\text { Tidak } \\
\text { Terpenuhi }\end{array}$} & \\
\hline & $\mathrm{N}$ & $\%$ & $\mathrm{~N}$ & $\%$ & \\
\hline Kontrol & 4 & 28,6 & 10 & 71,4 & 0,69 \\
\hline Perlakuan & 5 & 35,7 & 9 & 64,3 & 1 \\
\hline
\end{tabular}

Pada kelompok kontrol menunjukkan sebgaian besar responden kebutuhan tidurnya tidak terpenuhi yaitu sejumlah 10 responden $(71,4 \%)$. Sedangkan pada kelompok perlakuan menunjukkan bahwa 9 responden $(64,3 \%)$ kebutuhan tidur tidak terpenuhi

Berdasarkan uji satistik Mann-Whitney dengan dengan batas kemaknaan nilai $\alpha=5 \%$ ( $\mathrm{P}$ Value $<0,05)$, hasil pretest didapatkan tingkat signifikan 0,691 atau $>0,05$. Artinya 
tidak terdapat perbedaan yang signifikan antara kelompok kontrol dan kelompok perlakuan pada hasil pretest.

Tabel 5.5 Distribusi Frekuensi Hasil Postest Pemenuhan Kebutuhan Tidur

\begin{tabular}{|c|c|c|c|c|c|}
\hline \multirow{3}{*}{$\begin{array}{c}\text { Kelompo } \\
\mathbf{k}\end{array}$} & \multicolumn{4}{|c|}{$\begin{array}{c}\text { Pemenuhan } \\
\text { Kebutuhan Tidur }\end{array}$} & \multirow{3}{*}{$\mathbf{P}$} \\
\hline & \multicolumn{2}{|c|}{ Terpenuhi } & \multicolumn{2}{|c|}{$\begin{array}{c}\text { Tidak } \\
\text { Terpenuhi }\end{array}$} & \\
\hline & $\mathrm{N}$ & $\%$ & $\mathrm{~N}$ & $\%$ & \\
\hline Kontrol & 4 & 28,6 & 10 & 71,4 & 003 \\
\hline Perlakuan & 13 & 92,9 & 1 & 71,4 & \\
\hline
\end{tabular}

Pada kelompok kontrol menunjukkan sebagian responden kebutuhan tidurnya tidak terpenuhi yaitu sejumlah 10 responden $(71,4 \%)$ kebutuhan tidur tidak terpenuhi. Sedangkan pada kelompok perlakuan menunjukkan bahwa sebagian besar kebutuhan tidur terpenuhi yaitu sejumlah 13 responden $(92,9 \%)$.

Berdasarkan uji satistik Mann-Whitney dengan dengan batas kemaknaan nilai $\alpha=5 \%$ $(\mathrm{P}$ Value $<0,05)$, hasil postest didapatkan tingkat signifikan 0,003 atau $<0,05$. Artinya terdapat perbedaan yang signifikan antara kelompok kontrol dan kelompok perlakuan pada hasil postest.

Dari hasil uji statistik tersebut dapat disimpulkan bahwa $\mathrm{H} 1$ diterima, yang artinya ada pengaruh rendam kaki dengan air hangat terhadap pemenuhan kebutuhan tidur pada Pasien Preoperatif di Ruang Dahlia RSU Dr. H. Koesnadi Bondowoso.

\subsection{Pembahasan}

\section{Pemenuhan kebutuhan pasien preoperatif pada kelompok kontrol}

Dari hasil penelitian yang dilakukan pada kelompok kontrol, sebagian besar kebutuhuhan tidurnya tidak terpenuhi yaitu sejumlah 10 Responden $(71,4 \%)$. Salah satu faktor penyebab sebagian besar Pasien Preoperatif memiliki kebutuhan tidur yang tidak terpenuhi ialah faktor psikologis. Pada Pasien Preoperatif memiliki ketakutanketakutan dalam menghadapi proses pembedahan seperti takut terhadap nyeri dan kematian. Ketakutakan tersebut menimbulkan kecemasan yang memicu timbulnya gangguan dalam memenuhi kebutuhan tidurnya.
Menurut Asmadi (2009) kecemasan dapat menyebabkan gangguan pada frekuensi tidur. Hal ini disebabkan karena pada kondisi cemas terjadi peningkatan norepinefrin darah melalui saraf simpatis yang dapat mengganggu tahap IV NREM dan REM. Menurut Potter dan Perry (2009) kecemasan yang dialami membuat seseorang menjadi tegang dan berusaha keras untuk tertidur sehingga stres yang berlanjut dapat menyebabkan seseorang mempunyai kebiasaan tidur yang buruk.

Selain itu kemungkinan penyebab tidak terpenuhinya kebutuhan tidur Pasien Preoperatif pada kelompok kontrol di Ruang Dahlia RSU Dr. H. Koesnadi yaitu status kesehatan. Manifestasi klinis yang hampir muncul pada semua penyakit ialah nyeri. Keadaan nyeri membuat kualitas tidur sesorang menjadi terganggu. Oleh karena itu nyeri yang ditimbulkan oleh penyakit yang sedang diderita oleh Pasien dalam fase preoperatif menyebabkan gangguan dalam memenuhi kebutuhan tidurnya. Menurut Asmadi (2009) seseorang yang kondisi tubuhnya sehat memungkinkan ia dapat tidur dengan nyenyak. Tetapi pada orang yang sakit dan rasa nyeri, maka kebutuhan tidurnya tidak dapat terpenuhi dengan baik.

\section{Pemenuhan kebutuhan tidur Pasien Preopertif pada kelompok perlakuan}

Pada kelompok perlakuan sebelum dilakukan terapi rendam kaki dengan air hangat hanya 5 responden $(35,7 \%)$ yang kebutuhan tidurnya terpenuhi dan setelah dilakukan terapi rendam kaki dengan air hangat responden yang kebutuhan tidurnya terpenuhi meningkat menjadi 13 responden $(92,9 \%)$.

Tercukupinya kebutuhan tidur Pasien Preoperatif pada kelompok perlakuan setelah dilakukan rendam kaki dengan air hangat tersebut disebabkan karena tindakan tersebut menimbulkan efek relaksasi. Efek relaksasi tersebut memungkinkan pasien untuk lebih mudah terlelap tidur dan tidur menjadi lebih nyenyak sehingga kebutuhan tidur Pasien Preoperatif dapat terpenuhi.

Air hangat dapat mengendorkan otot sekaligus memiliki efek analgesik. Tubuh yang lelah akan menjadi segar dan mengurangi rasa letih yang berlebihan (Ningrum, 2012). Sedangkan menurut Knight (1997, dalam Khotimah, 2012) efek panas pada air 
cenderung melebarkan pembuluh darah, terutama pada permukaan dan ini membawa lebih banyak darah ke bagian yang dipanaskan, selain itu akan menyebabkan relaksasi.

Tercukupinya kebutuhan tidur Pasien Preoperatif pada kelompok perlakuan setelah dilakukan rendam kaki dengan air hangat tersebut disebabkan karena tindakan tersebut menimbulkan efek relaksasi. Efek relaksasi tersebut memungkinkan pasien untuk lebih mudah terlelap tidur dan tidur menjadi lebih nyenyak sehingga kebutuhan tidur Pasien Preoperatif dapat terpenuhi.

Menurut Ningrum (2012) Air hangat dapat mengendorkan otot sekaligus memiliki efek analgesik. Tubuh yang lelah akan menjadi segar dan mengurangi rasa letih yang berlebihan. Sedangkan menurut Knight (1997, dalam Khotimah, 2012) efek panas pada air cenderung melebarkan pembuluh darah, terutama pada permukaan dan ini membawa lebih banyak darah ke bagian yang dipanaskan, selain itu akan menyebabkan relaksasi.

Berdasarkan hasil penelitian Widiastuti (2015) hidroterapi rendam kaki air hangat membantu menurunkan nyeri pada Pasien Post Operasi. Dari 17 responden penelitian, ratarata intensitas nyeri post operasi sebelum intervensi diberikan adalah 4,06, sedangkan setelah intervensi diberikan mengalami penurunan menjadi 2,71 .

Terapi rendam kaki dengan air hangat memicu bagian tertentu di dalam otak yang menimbulkan efek ingin tidur. Efek yang didapat tersebut memungkinkan pasien preoperatif dapat memenuhi kebutuhan tidurnya dengan baik. Menurut Guyton (2007 dalam Ningtyas, 2014) bahwa rendam kaki dengan air hangat dapat menstimulus syarafsyaraf kulit pada kaki yaitu flexusvenosus dari rangkaian syaraf ini stimulasi diteruskan ke kornus posterior kemudian dilanjutkan ke medulla spinalis, dari sini diterukan ke lamina I, II, III radiks dorsalis, selanjutnya ke ventro basal thalamus dan masuk ke batang otak yang tepatnya didaerah raafe bagian bawah pons dan medulla disinilah terjadi efek sofarifik (ingin tidur).

Pengaruh rendam kaki dengan air hangat
terhadap pemenuhan tidur pada Pasien
Preoperatif

Pengaruh rendam kaki dengan air hangat Preoperatif
Berdasarkan uji satistik Mann-Whitney dengan dengan batas kemaknaan nilai $\alpha=5 \%$ ( $\mathrm{P}$ Value $<0,05)$, hasil pretest didapatkan tingkat signifikan 0,769 atau $>\alpha(0,05)$. Artinya tidak terdapat perbedaan yang signifikan antara kelompok kontrol dan kelompok perlakuan pada hasil pretest. Dan pada hasil postest didapatkan tingkat signifikan 0,003 atau $<\alpha(0,05)$. Artinya tidak terdapat perbedaan yang signifikan antara kelompok kontrol dan kelompok perlakuan pada hasil postest. Dari hasil uji statistik tersebut dapat disimpulkan bahwa $\mathrm{H} 1$ diterima, yang artinya ada pengaruh rendam kaki dengan air hangat terhadap pemenuhan kebutuhan tidur pada Pasien Preoperatif di Ruang Dahlia RSU Dr. H. Koesnadi Bondowoso.

Berdasarkan hasil penelitian rendam kaki dengan air hangat membantu meningkatkan kualitas tidur sehingga kebutuhan tidur dapat terpenuhi. Hal tersebut dapat dilihat pada tabel 5.4 dan tabel 5.5 tentang pemenuhan kebutuhan tidur sebelum dan sesudah diberikan terapi rendam kaki dengan air hangat. Pada kelompok perlakuan sebelum dilakukan terapi rendam kaki dengan air hangat hanya 5 responden $(35,7 \%)$ yang kebutuhan tidurnya terpenuhi dan setelah dilakukan terapi rendam kaki dengan air hangat responden yang kebutuhan tidurnya terpenuhi meningkat menjadi 13 responden $(92,9 \%)$. Sedangkan pada kelompok kontrol responden yang kebutuhan tidurnya terpenuhi tidak mengalami peningkatan yaitu tetap 4 responden $(28,6 \%)$.

Hasil tersebut sesuai dengan penelitian yang dilakukan oleh Khotimah (2012) yang berjudul "Pengaruh Rendam Air Hangat Pada Kaki Dalam Meningkatan Kuantitas Tidur Lansia" didapatkan Hasil analisis menunjukan kuantitas tidur lansia yang dilakukan rendam air hangat pada kaki mengalami peningkatan, dengan nilai signifikansi 0,0001 atau $<\alpha(0,05)$ artinya ada pengaruh rendam air hangat pada kaki dalam meningkatkan kuantitas tidur pada lansia. Hasil penelitian menunjukkan bahwa rendam air hangat pada kaki efektif digunakan untuk meningkatkan kuantitas tidur pada lansia yang mengalami gangguan tidur.

Rendam kaki dengan air hangat dapat menstimulus syaraf-syaraf kulit pada kaki yaitu flexusvenosus dari rangkaian syaraf ini stimulasi diteruskan ke kornus posterior 
kemudian dilanjutkan ke medulla spinalis, dari sini diterukan ke lamina I, II, III radiks dorsalis, selanjutnya ke ventro basal thalamus dan masuk ke batang otak yang tepatnya didaerah raafe bagian bawah pons dan medulla disinilah terjadi efek sofarifik (ingin tidur) (Guyton, 2007 dalam Ningtyas, 2014).

\section{Kesimpulan Dan Saran \\ 5.1 Kesimpulan}

Berdasarkan hasil penelitian yang telah dilakukan dapat di tarik kesimpulan sebagai berikut:

1. Pemenuhan kebutuhan tidur Pasien Preoperatif pada kelompok kontrol di Ruang Dahlia RSU Dr. H. Koesnadi sebagian besar kebutuhan tidurnya tidak terpenuhi.

2. Pemenuhan kebutuhan tidur Pasien Preoperatif pada kelompok perlakuan di Ruang Dahlia RSU Dr. H. Koesnadi sebelum diberikan perlakuan sebagian besar kebutuhan tidurnya tidak terpenuhi, sedangkan setelah diberikan perlakuan sebagian besar kebutuhan tidur terpenuhi.

3. Ada pengaruh rendam kaki dengan air hangat terhadap pemenuhan kebutuhan tidur pada Pasien Preoperatif di Ruang

5.2 Saran

Dahlia RSU Dr. H. Koesnadi Bondowoso.

Berdasarkan hasil penelitian ini, disarankan bagi:

1. Bagi Perawat

Perawat dapat menerapkan rendam kaki dengan air hangat pada pasien preoperatif untuk meningkatkan pemenuhan kebutuhan tidur pada pasien preoperatif untuk menjaga agar tubuh tetap berfungsi dengan baik dalam persiapan menghadapi pembedahan.

2. Bagi Peneliti selanjutnya

Bagi Peneliti selanjutnya sebaiknya dilakukan penilaian pemenuhan kebutuhan tidur tidak hanya satu malam saja dan dilakukan penilaian juga pada tidur siang.

3. Bagi Pasien Preoperatif

Pasien preoperatif dapat menyiapkan operatsi dengan tubuh yang prima, salah satunya dengan memnuhi kebutuhan tidur sesuai kebutuhan.

\section{DAFTAR PUSTAKA}

Asmadi. 2009. Teknik Prosedural Keperawatan: Konsep dan Aplikasi. Jakarta : Salemba Medika.

Baradero, M., Dayrit, M.W., Siswadi, Y. 2009. Prinsip dan Praktik Keperawatan Perioperatif. Jakarta: EGC

Hasri, E.T., Hatriyanti, Y., Haryanti, F. 2012. Praktik Keselamatan Pasien Bedah di Rumah Sakit Daerah. Jurnal Manajemen Pelayanan Kesehatan. Vol.15 (04), hal 198-202.

http://download.portalgaruda.org/ diakses pada tanggal 17 November 2015.

Lumbantobing. 2008. Gangguan Tidur. Jakarta: Fakultas Kedokteran Universitas Indonesia.

Muttaqin, A., Sari, K. 2009. Asuhan Keperawatan perioperatif: Konsep, Proses, dan Aplikasi. Jakarta: Salemba Medika.

Ningrum, D.A. 2012. Perbandingan Metode Hydrotherapy Massage dan Massage Manual Terhadap Pemulihan Kelelahan Pasca Olahrga Aerobic Lactacid. http://repository.upi.edu/ diakses pada tanggal 17 November 2015.

Ningtyas, A.P. 2014. Pengaruh Rendam Kaki Dengan Air Hangat Terhadap Kualitas Tidur Di Dusun Mangiran. http://opac.unisayogya.ac.id/ Diakses pada tanggal 11 januari 2016.

Potter, P.A., Perry, A.G. 2009. Fundamental Keperawatan, Buku 3, Edisi 7. Jakarta: Salemba Medika.

Utami, Titis. 2015. Pengaruh Rendam Air Hangat pada Kaki Terhadap Insomnia pada Lansia di Panti Sosial Tresna Werdha Yogyakarta Unit Budi Luhur. http://opac.say.ac.id/ diakses pada tanggal 17 November 2015. 
ISSN : 2354-5852

e-ISSN : 2579-5783

Widiastuti, L.T. 2015. Pengaruh Hidroterapi Rendam Kaki Air Hangat Terhadap Penurunan Nyeri Pasien Post Operasi Di Rumah Sakit Islam Sultan Agung Semarang. http://www.academia.edu/ diakses pada tanggal 22 Juni 2016. 